\title{
Sand body prediction of Fuyu Oil layer in 401 block, Sanzhao Depression, Songliao Basin Xin Liu ${ }^{1, a}$, Zhaonian Chen ${ }^{1, b}$, Shubo Chen ${ }^{1, c}$ \\ ${ }^{1}$ School of Energy Resources, China University of Geosciences, Beijing 100083, China a253710226@qq.com, ${ }^{\text {b}} 517033595 @ q q . c o m,{ }^{c}$ chenshubo853@163.com
}

Keywords: Songliao Basin, Sanzhao Depression, Fuyu oil layer, sand body prediction.

\begin{abstract}
This paper takes Sanzhao Depression in Songliao Basin as the research target, Fuyu oil layer in Sanzhao Depression is an important petroleum exploration field, it is in the 4th member of Quantou formation, Lower Cretaceous. The target layer in research area is mainly a set of shallow-water delta deposition. Because of the distributary channel frequently swing, single sand body thin thickness, study of sand body prediction must be carried out to guide further petroleum development. In the case of lack of core data, this study use the method of geostatistical inversion to predict sand body. The sedimentary facies make a certain control to the sand body distribution.
\end{abstract}

\section{Introduction}

Sanzhao Depression is the secondary tectonic units of Songliao Basin which is also part of a first-order tectonic unit-the central depression. The 4th member of Quantou formation is mainly shallow-water delta deposition, includes two sub facies: Delta front and Delta plain. It is a third order sequence which can be divided into three fourth order sequence [1]. On the basis of the identification of the base-level cycle, Fuyu oil layer can be divided into three mid-term cycle and further divided into five short-term cycle [2]. The main hydrocarbon source rock is in the 1st member of Qingshankou formation and over-pressurized oil migrated down to Fuyu Formation below through the opened faults [3].

This paper on the basis of a comprehensive collection of seismic and logging data, deeply investigated the distribution of sand body. The study provides strong supports and directions for future exploration of Fuyu oil layer.

\section{Geological setting}

Sanzhao Depression is located in the northern part of Songliao Basin. It is a secondary tectonic unit of central depression, with area about $82 \mathrm{~km}^{2} .401$ block located in southern part of Zhaozhou nose structure in Sanzhao Depression. It is the main oil and gas enrichment zone, with area about $82 \mathrm{~km}^{2}$ (Fig. 1). The target layer of this research is Fuyu oil layer in the 4th member of Quantou formation, its buried depth range is about from $-1600 \mathrm{~m} \sim-2075 \mathrm{~m}$, its thickness is about $225 \mathrm{~m}$. 


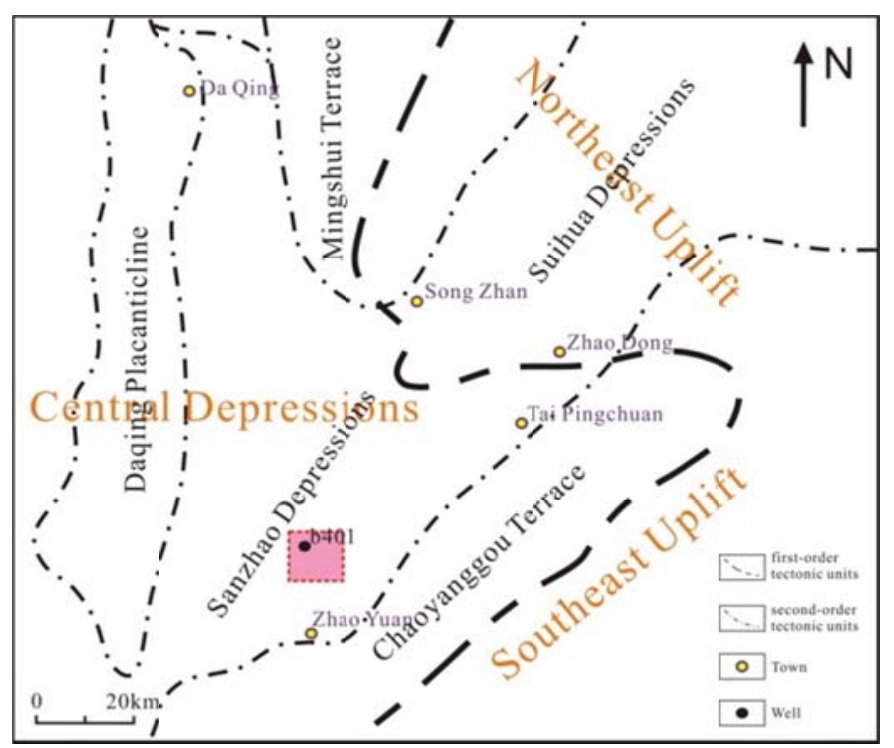

Fig. 1 Geographic location of the study area

\section{Sand body prediction}

\subsection{Geostatistical inversion}

On the basis of logging curve standardization, The SP and GR curves are used to consist new impendence curve, further, carried out impendence inversion [4].

Horizon calibration and wavelet extraction are the key to geostatistical inversion, they influenced and checked each other. In this research, use AC curve to compare with near-well seismic traces carefully, as a result, get the time-depth table (Fig. 2). During wavelet extraction process, firstly, build a theoretical Ricker wavelet to make synthetic records and adjust time-depth table, then, extract new wavelet according to synthetic records, making new synthetic records through adjusting related wavelet parameters repeatedly. Repeating the process until synthetic record matches near-well seismic traces very well, the latest wavelet which is needed.

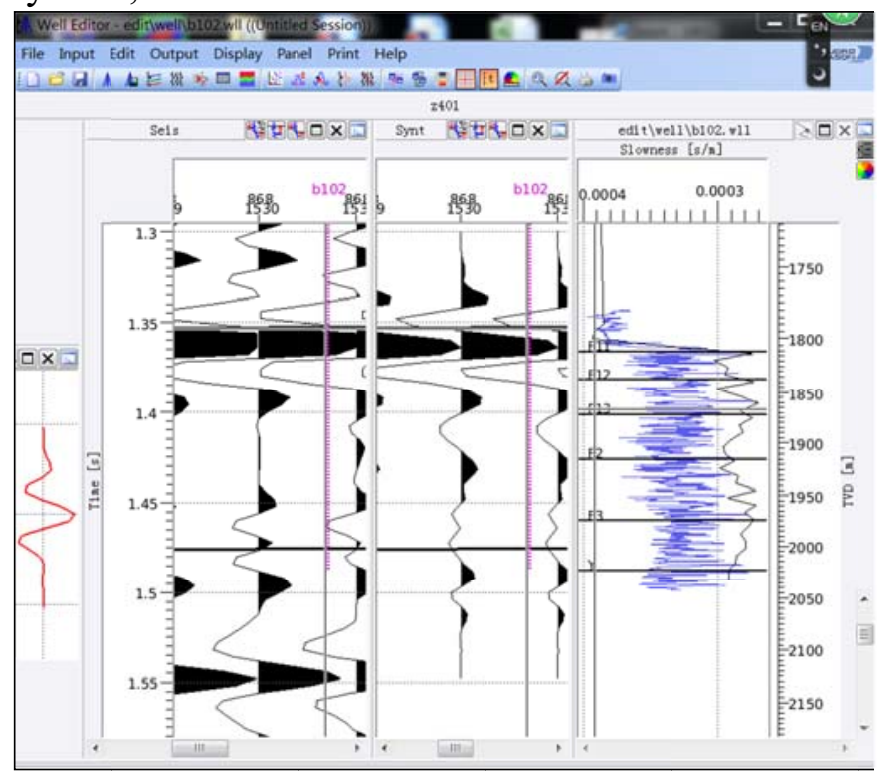

Fig. 2 Synthetic seismogram

On the basis of seismic horizons information, build geological framework by the law of sedimentary of Fuyu oil layer, set up 3D seismic data of low frequency wave impedance model for study area. Then use the established model, under the constraints of curve data, convert seismic volume to impedance volume. With constrain and adjustment of different kinds of quality control module, get the most accuracy impendence inversion by modifying repeatedly (Fig. 3). 


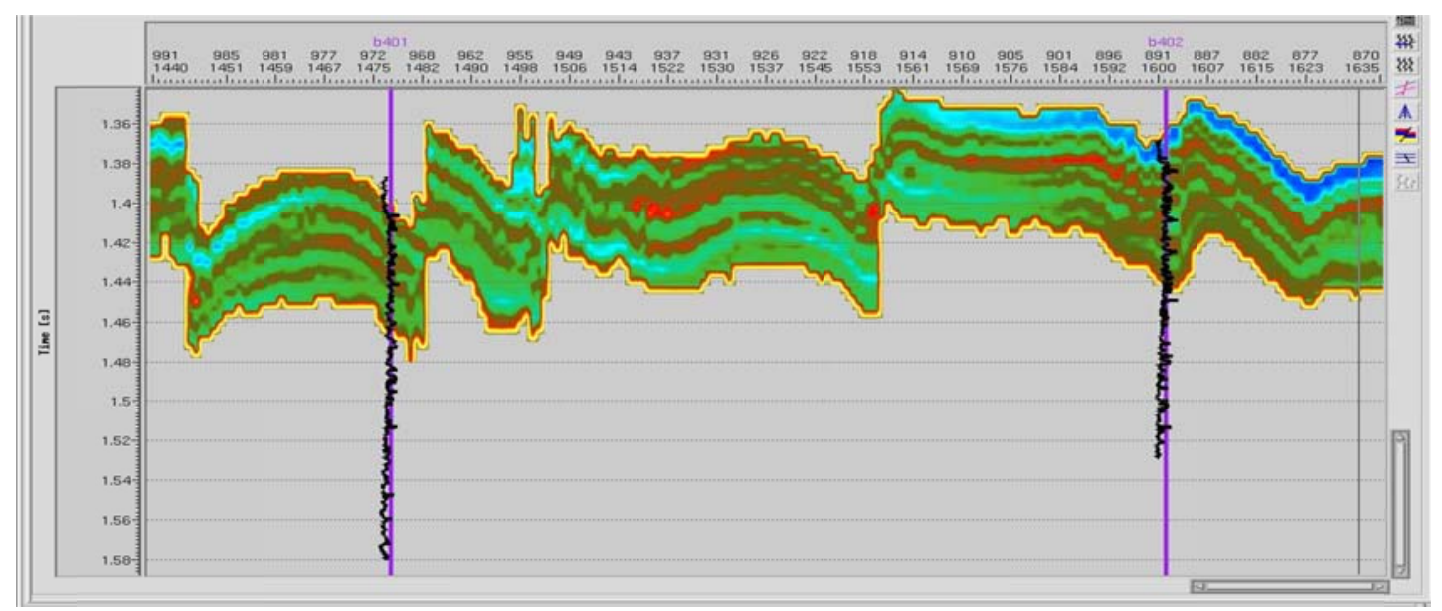

Fig. 3 Inversion profile(b401-b402)

Based on the geostatistical inversion, gained the impendence-lithology table by analyzing impendence and curve which stand for sandstone or others. The table plays an important role in transform between impendence volume and lithology volume (Tab. 1).

Tab. 1 Corresponding relation between impedance and lithology

\begin{tabular}{|c|c|}
\hline Impedance $\left(\mathrm{Kg} / \mathrm{m}^{3} \cdot \mathrm{m} / \mathrm{s}\right)$ & Lithology \\
\hline $7.6 \sim 9.7 \times 10^{6}$ & Sand \\
\hline $6.1 \sim 7.6 \times 10^{6}$ & Others \\
\hline
\end{tabular}

\subsection{Sand body distribution}

The sand body of FIII reservoir group has significantly different distribution, its thickness is from $6 \mathrm{~m}$ to $17 \mathrm{~m}$. Large sand thickness area is in the central region of the study area, the sand body has banding distribution, reflects the distributary channel developed (Fig. 4).

The sand thickness of F II reservoir group is from $7 \mathrm{~m}$ to $16 \mathrm{~m}$, and distributed evenly. F II reservoir group has the largest average thickness of sand body, about $11 \mathrm{~m}$ (Fig. 5).

The sand thickness of F I 3 reservoir group is from $5 \mathrm{~m}$ to $10 \mathrm{~m}$, large sand thickness area is mainly in the northwest and southwest area (Fig. 6).

The sand thickness of F I 2 reservoir group is from $5 \mathrm{~m}$ to $10 \mathrm{~m}$, large sand thickness area is mainly in the central region (Fig. 7).

The sand thickness of F I 1 reservoir group is from $4 \mathrm{~m}$ to $8 \mathrm{~m}$, pieces-link sand only developed in the central region of the study area (Fig. 8).

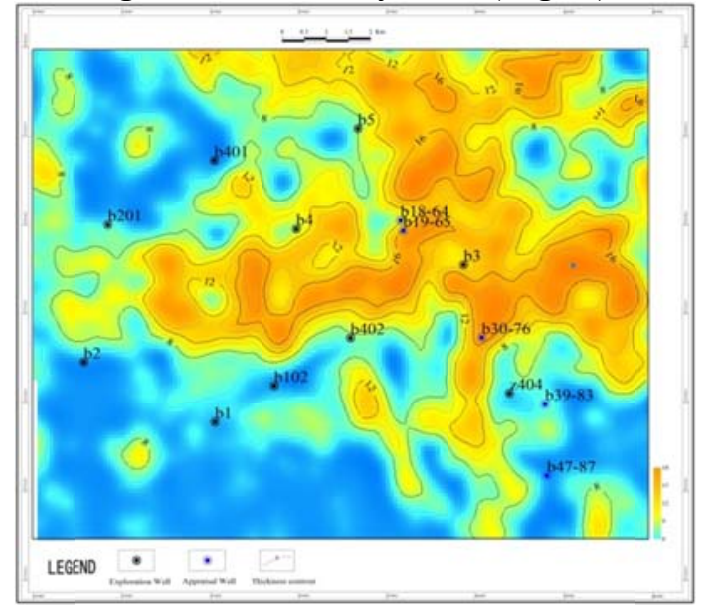

Fig. 4 Thickness of sand body in FIII group

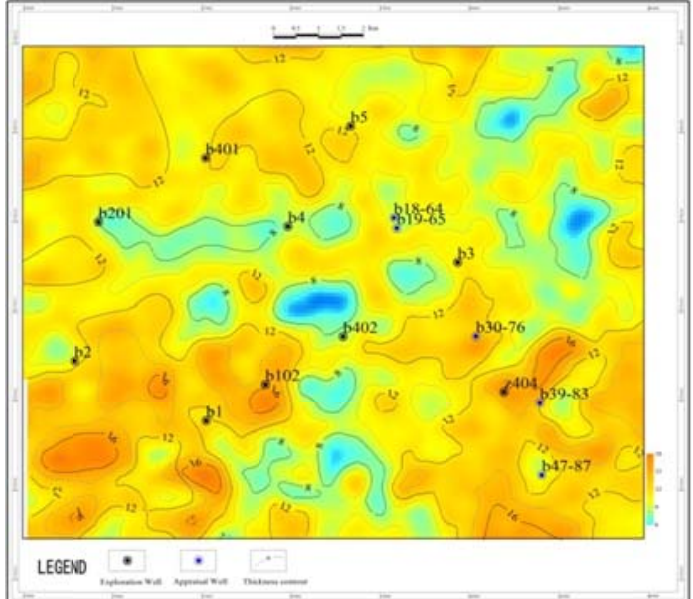

Fig. 5 Thickness of sand body in F II group 


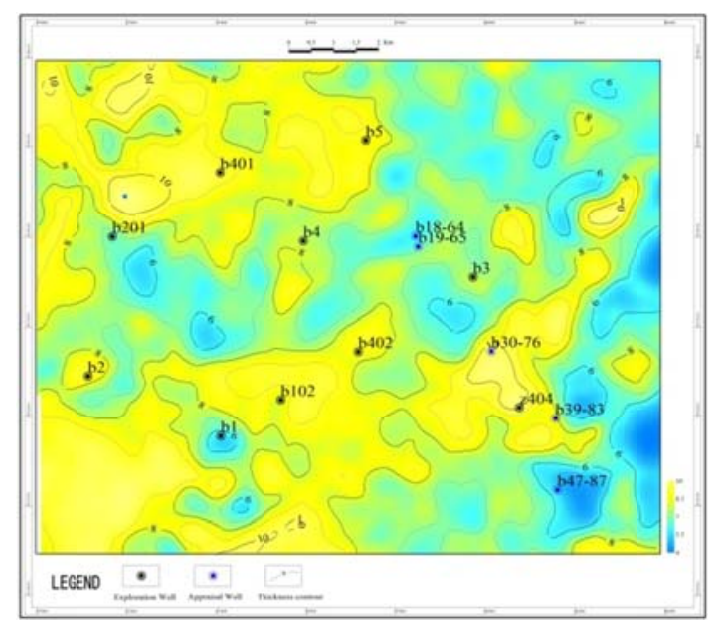

Fig. 6 Thickness of sand body in F I 3

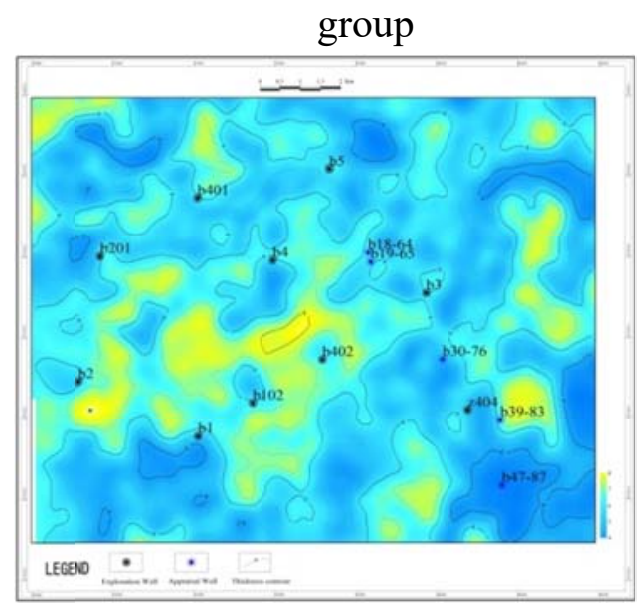

Fig. 8 Thickness of sand body in F I 1 group

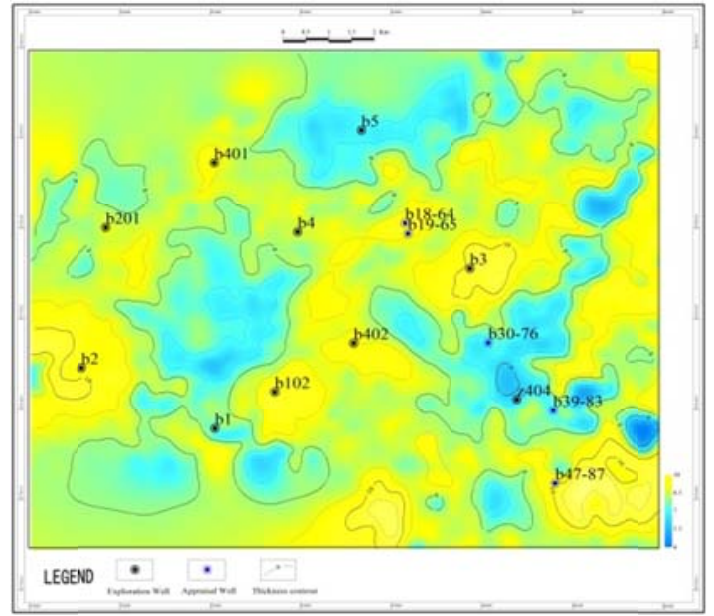

Fig. 7 Thickness of sand body in F I 2 group

\section{Summary}

This paper use the method of geostatistical inversion to predict sand body, which absorb the advantages of seismic inversion and random model predication, combining seismic and logging data to increase the resolution of target layer, effectively identified small thickness sand bodies. As a result, accurately predict the distribution of sand body in each group. F II reservoir group has the largest average thickness of sand body, about $11 \mathrm{~m}$.

\section{References}

[1] Mingyi Hu, Chunyan Sun, Dan Xue, Hongjun Zhang. Study of high resolution sequence stratigraphy of Quan 4th member, Sanzhao area in the northern Songliao Basin. GEOSCIENCE. 2015, 29(4), 765-776.

[2] Hongwen Deng, Haibo Wu, Ning Wang, Timothy A. Cross. Division of fluvial sequence stratigraphy - an example from the Lower Cretaceous Fuyu oil layer, Songliao Basin. OIL \& GAS GEOLOGY. 2008, 28(5).

[3] Baoxiang Tan, Deyan Hou, Jinghua Lin. Hydrocarbon distribution and exploration potential of the Fuyu-Yangdachengzi petroleum pays, Sanzhao Depression, Songliao Basin. Petroleum Exploration and Development. 1995, 22(1), 1-5.

[4] Alistair R. Brown. Seismic attributes and their classification. The Leading Edge. 1996, 15(10):1090 1099. 